\title{
Study on the Barriers to Crossing the Western and Chinese Cultures
}

\section{Fengyun Nie}

\author{
Weinan Normal University, Weinan, Shaanxi, 714000
}

Keywords: Across, cultural differences between China and the West, cultural conflicts, obstacles.

\begin{abstract}
As transnationalities and intercultural exchanges become more frequent and frequent, cultural differences between China and the West due to differences in values, social norms and cultural norms have led to the emergence of cultural "collision" or " Conflict "phenomenon, this phenomenon will lead to barriers to communication, serious or even cause misunderstanding on both sides of the communication. Therefore, to understand and analyze the causes of this "conflict" and to cross the barriers between Chinese and Western cultures is conducive to overcoming the cultural differences between China and the West and avoiding the "conflict" of culture so that communication can proceed smoothly.
\end{abstract}

With the rapid development of modern computer technology and the continuous development of the information revolution, China has become a member of the World Trade Organization (WTO) successfully. China's accession to taboos for transnational, inter-ethnic and inter-cultural economic or cultural exchanges will increase with each passing day This provides many opportunities for us to meet and interact with foreigners. However, it is not a simple matter to contact and communicate with foreigners because we are faced with an unfamiliar culture, an unfamiliar country, A group of strange ways of thinking, habits and behaviors. The biggest obstacle we encounter in the actual communication process comes from the differences in culture and customs arising from different values and ways of thinking. People from different cultural backgrounds have very different ways and habits of speaking. Each has its own language protocol or living habits. Under such circumstances, if one party does not understand the social and cultural traditions and cultural habits of the other party, Communication will produce cultural conflicts or communication barriers, serious or even cause misunderstanding, therefore, to study and analyze the cultural differences in the process of communication due to cultural conflicts have a very important practical significance.

What is "culture"? The English of "culture" is culture, one of the three most complex words in English. The reason is that the definition of "culture" is difficult to determine. According to Professor Hu Wenzhong's quotation of Keluobo and Karakhong, there are at least 150 definitions of "culture." According to Professor Qi Yucun, there are currently no less than 250 definitions of "culture" in the world. Therefore, to elaborate "culture" accurately, it is difficult to give a "scientific" and "complete" definition of "culture." "Cihai" defines "culture" as follows: In a broad sense, "culture" refers to the synthesis of material wealth and spiritual wealth created during the historical time of human society. It includes all-encompassing human knowledge, beliefs, art and morality Laws, customs and habits all belong to the category of culture.

It also means that the formation of culture does not happen overnight, and its establishment and evolution have been completed. It has been through the sublation of a long time and the management and development of people from generation to generation, including the geographical environment and standard of living in that area, Economic, political development, ethnic differences and many other factors come together into a culture like a sea, it can accept and absorb all the foreign things, but it will also devour many lives, but also will not belong to many As the wave of ocean to the shore, let it receive the sun exposure, and eventually disappear in this world. As Sapir, the eminent linguist in the United States, put it: "The language can not exist without culture and can not be practiced in all ways and beliefs inherited from society" (E. Sapir, 1921: 221). Culture is the sum of material products and spiritual products created by human beings. It embodies the values, 
behaviors, literary arts, customs, lifestyles and political systems possessed by human groups. All these are the crystallization of culture; it is a mirror of culture.

The differences between Chinese and Western cultures are reflected in the notable difference in the notion of time. The Americans insist on monochromic-time patterns. They think that "time is the concept" places great emphasis on the agenda, the stage Sex and timeliness (punctuality) of the time habits, everything should be done strictly according to the schedule, one can only do one thing, do a good job and then continue to the next thing, what should be done, If not completed at a given time, it should be completed immediately, proceed to the next thing, can not happen to suspend the next thing to ensure the continuation of the last piece of uncompleted, nor to allow the next guest to continue Waiting for the Americans, the agreement, it means your credibility and commitment, it should be strictly to comply with, resolutely to implement, appointment and punctuality is a social rule advocated by everyone and the community Time is of extraordinary importance to those who come to the one-way time habits. People attach great importance to the effectiveness of time, the use of reasonable, especially for those who do not know interesting "waste" of time and the behavior of other people, Americans are quite disgust and repulsion. In daily life, Americans make elaborate plans for time, and in the life has formed a sophisticated arrangement and calculation of time, a good habit of punctuality, once you have agreed with others, you must strictly abide by If you are unable to make an appointment due to unpredictable reasons, you should promptly call to inform the other party about your apology and inform the other party about the approximate time it will take you to reach the appointment. If you can not reach the appointment, you should cancel the appointment, and should apologize to each other, beg forgiveness. In the life will be arranged in time enough compact, we often see that in the United States on the streets or in places such as stations, people take tickets and travel, are arranged in a well-organized manner, less likely to appear in China Crowds of people rush into the vehicle.

In contrast, China's lifestyles and attitudes toward time are more biased toward the diversity of time models. The diversity of time patterns is relatively more arbitrary for timing and usage. For Chinese people, compliance and time to comply are important, but not as strict and meticulous as the Westerners. What to do when they do this may not be done according to established arrangements, if you do not finish it on time and do not immediately start the next job, most people will choose to continue doing the work at hand and piling up the next one until the next one, and the end will not end on time, the beginning of the seldom started in time, which has caused most Chinese people have problems: "procrastination." Things like this can often be said to be happening around us: when traveling by train, we should not go out on time and stay at home until we can no longer procrastinate and hurry to go out at the last minute. With chaos The crowd crowded into the team, what is more, the train is coming soon, and the ticket window of the team there is a long queue, rushed directly to the front, please others to give priority to their vote, and most Chinese practices Understand the situation so that they first completed the ticket to catch the train, which is not cherish their own time, while occupying and waste time of others behavior, but most Chinese are practicing such a lifestyle and time habits. The Chinese will abide by the agreement, but their understanding of the agreement is not as harsh as that of the Westerners. There is a huge difference between its "arbitraryness" and the "unshakeable" agreement in the West. Very often, for a good time, for Westerners, this period of time should belong to both parties completely, impossible or forbidden to be interrupted or forcibly interfered with by other things, and the Chinese are in agreement with each other Of the time, sometimes distracted by anything else and distracted, or may deal with another matter that is completely unrelated to the agreement within the agreed time frame.

Obstacles to Chinese and Western culture are also reflected in one aspect, namely, the educational outlook on children, the values influenced by the individual in the Western culture, the pursuit and emphasis on individual independence, which are especially prominent in the United States; in the United States, elders in particular Focus on cultivating children's independence. When their children are young, elders begin to indoctrinate their independence and independent consciousness. In their daily activities, children are encouraged to do their own thing without the 
help of parents. When you were young, you should cultivate yourself and eat. You earn your pocket money instead of asking for help from your parents. When you fall, you will get up instead of sitting on the ground. Waiting for your parents to help you, Western countries will also pay more attention to privacy awareness Children have their own, independent space. Parents generally do not interfere in their children's freedom and private affairs. They even include marriage. Children in the United States have become independent and self-reliant since the age of 18, Individuals who are responsible for their actions.

The Chinese are the opposite in this respect because the cultural environment in China for thousands of years has advocated "peace", "peace is our goal" and "helping each other". In China, the slogans of residential areas are everywhere in emphasizing the unity, harmony, friendship, mutual dependence and mutual assistance among people, most Chinese parents have a strong desire to control their children. They like to tell their children that they should What to do, what to do, what to do and what to do absolutely. In the process of getting along with children, parents in China prefer to spoil their children, protect children with nothing, dress, eat, brush their teeth, etc. Things that should have been done by themselves are all arranged for the children. When the children are adults, the parents will continue to interfere in the marriage of the children. They will continue to organize a large number of blind dates for their children and pick up the other half Give children. As children grow up, they also intervene at important moments in the life cycle, such as choosing a school, choosing a major, and letting children complete their dreams that they have not yet completed or can not complete and dominate most of their children's lives. Although there are many underage minorities in China, including Tsinghua University and Peking University, which are among the top universities in China, one of the common characteristics of these students is that they are too dependent and dependent on their parents to leave their parents' wings Being unable to live independently and losing their ability to take care of themselves also weakens the exchange and cooperation with their peers around them, becoming good friends, realizing the opportunities of friendship, and taking up too much part in the lives of some children. Life is not unsuccessful, but incomplete, not successful.

On December 7, 2017, Chinese actor Liu Yifei stood out from nearly 1,000 candidates on five continents and will star in the Disney movie "Mulan." This news is undoubtedly supported by the people of both China and the United States. Is a major leap in cultural exchange between China and the West, Mulan is Disney's eighth official princess, and Liu Yifei will be the first Disney live-action Asian princess. Liu Yifei starred in Mulan, the Chinese and American filmmakers cheered, behind the high-quality resources, the Chinese film and Chinese cultural soft power "sea of heat." Also worth noting is that the official Disney platform and "Hollywood Reporter" state the official confirmation of the release: Liu Yifei Has Been Cast as \# Mulan in the Upcoming Live-Action Film: di.sn/6010DEGpQ While this passage may seem like a mere factual statement, it is common in Western cultures to write a Chinese name, with the last name first, and the family name Behind, in this passage, Liu Yifei's name is spelled Liu Yifei instead of Yifei Liu. This shows that both China and the West have been studying each other's culture and respecting each other during the years of constant collision and exchange of Chinese and Western Cultures Culture and customs have taken an important stride. Behind the same incident, they represent not only the continuous development of science and technology and the continuous prosperity of culture, but also the gradual history and replacement of the collision and conflict between China and the West. The culture is highly prosperous and moving forward in a relatively peaceful environment.

\section{References}

[1] On the relationship between Chinese and Western time viewpoints and the cultivation of intercultural communicative competence in Chinese international teaching, Ren Le - "Jiannan Literature: Classics Reading" - 2013 - Cited by: 1. Source: Wanfang / Love academic

[2] Analysis of the Intercultural Communication Barrier of the Movie "The 13 Girls of Jinling" The Cultural Conflict Prominent in the Case of the "13 Days of Jinling" Written by Western Media, 
for example, Ke Wei - "Movie Review" - 2012 - Quotations: 5

[3] Analysis of the Collectivism's Influence on Cross-sectoral Synergy - Based on the Comparison of Chinese and Western Culture, Jiang Minjuan - "Yunnan Social Sciences" - 2016 - Cited: 0

[4] Transcending, Freeing and Surpassing between East and West - Reading New Perspective of Prof. Long Denggao, "Barriers to Crossing the Market: Overseas Chinese Entrepreneurs in the Country, System and Culture" Succeed, Starry Sky - "Historical Studies of Overseas Chinese" $2007-1$

[5] On the cultural differences between China and the West on the impact of intercultural communication, Wu Qing, Li Xiaohong, Zhejiang Institute of Media "Questions and Research: New Curriculum Forum" 2016 12, 123-124. 